\title{
Durga Method of Squaring A Circle
}

\section{RD Sarva Jagannadha Reddy}

Abstract: Squaring of circle is an unsolved problem with the official $\pi$ value $3.1415926 \ldots$ with the new $\pi$ value $1 / 4(14-\sqrt{2})$ it is done in this paper.

Keywords: Exact Pi value $=1 / 4(14-\sqrt{2})$, Squaring of circle, Hippocrates squaring of lunes.

\section{Introduction}

Squaring a circle is defined as constructing a square having an area equal to that of a given circle. It is also called as quadrature of the circle.

This concept has been there from the days of Rhind Papyrus (1800 B.C) written by a scribe named Ahmes. Hippocrates of Chios (450 B.C) has squared lunes, full circle and semicircle along with lunes. He fore saw the algebraic nature of the $\pi$ value. $\pi$ value $3.1415926 \ldots$ has failed to find a place for it in the squaring of lunes. Though the World of Mathematics has accepted his squaring of lunes, they became silent for why $3.1415926 \ldots$ is a misfit in his constructions. Further, there is a false opinion that Hippocrates could not square a circle. However, Hippocrates did square a full circle and a semicircle along with a lune. In both the cases squaring a lune, squaring a circle along with a lune - the new $\pi$ value, $\frac{14-\sqrt{2}}{4}$ has explained perfectly well the constructions of Hippocrates. Thus the propositions of Hippocrates which remained theoretical all these 2400 years, have become practical constructions with the discovery of $\frac{14-\sqrt{2}}{4}$. It is clear therefore, we have misunderstood Hippocrates because, we believed 3.1415926... as the value of $\pi$. I therefore apologize to Hippocrates on behalf of mathematics community for the past mistake done by us. And to atone the academic sin committed by us, I bow my head and dedicate the explained parts (for details: Pi of the Circle, last chapter: Latest work, Pages from 273 to 281) to Hippocrates, in www.rsjreddy.webnode.com

James Gregory (1660) has said squaring of circle is impossible. His view has been confirmed by C.L.F. Lindemann (1882) based on Euler's formula $\mathrm{e}^{\mathrm{i} \pi}+1=0$. Von K. Weiertrass (1815-1897) and David Hilbert (1893) have supported the proof of Lindemann by their proofs.

S. Ramanujan (1913) has squared a circle upto some decimals of 3.1415926... Prof. Underwood Dudley doesn't accept Lindemann's proof because this is based on numbers which are approximate in themselves.

Now, the exact $\pi$ value is discovered. It is $\frac{1}{4}(14-\sqrt{2})$. It is an algebraic number. The following is the procedure how to square a circle.

\section{Procedure}

We have to obtain a side of the square whose value is $\frac{1}{2} \sqrt{\pi}$; when $\pi=\frac{14-\sqrt{2}}{4}$, then $\frac{1}{2} \sqrt{\pi}=\frac{1}{2} \sqrt{\frac{14-\sqrt{2}}{4}}=\frac{\sqrt{14-\sqrt{2}}}{4}$

$\mathrm{CD}=\mathrm{a}, \mathrm{OK}=\mathrm{OF}=$ radius $=\frac{a}{2}, \mathrm{FK}=\frac{\sqrt{2} a}{2}, \mathrm{JK}=$ $\mathrm{FG}=\mathrm{GC}$,

$\mathrm{GC}=(\mathrm{JG}-\mathrm{KF}) \frac{1}{2}=\left(\mathrm{a}-\frac{\sqrt{2} \mathrm{a}}{2}\right) \frac{1}{2}=$

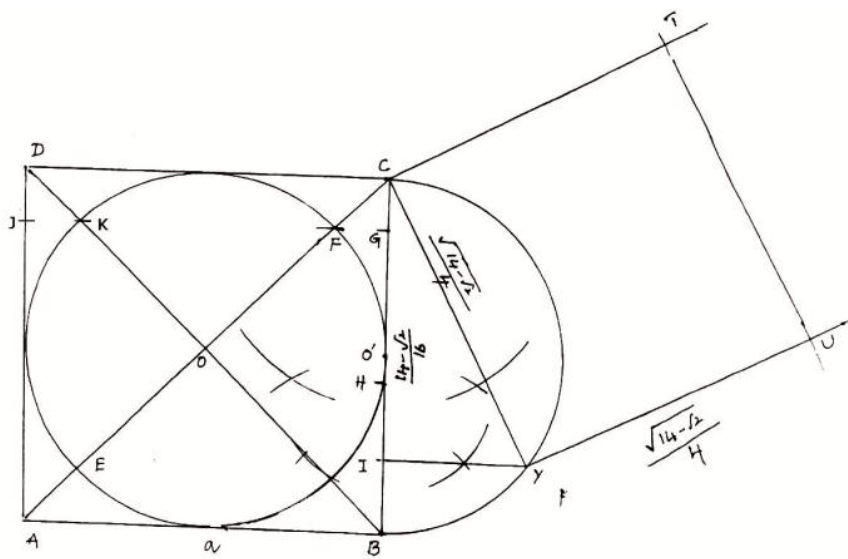


$\left(\frac{2-\sqrt{2}}{4}\right) \mathrm{a} ; \mathrm{GB}=\mathrm{BC}-\mathrm{GC}=\mathrm{a}-\left(\frac{2-\sqrt{2}}{4}\right) \mathrm{a}=\left(\frac{2+\sqrt{2}}{4}\right) \mathrm{a} ;$

Bisect GB. $\mathrm{GH}=\mathrm{HB}=\left(\frac{2+\sqrt{2}}{8}\right) \mathrm{a}$. Bisect HB. $\left(\frac{2+\sqrt{2}}{16}\right) \mathrm{a}=\mathrm{HI}=\mathrm{BI}$

$\mathrm{CI}=\mathrm{BC}-\mathrm{BI}=\mathrm{a}-\left(\frac{2+\sqrt{2}}{16}\right) \mathrm{a}=\left(\frac{14-\sqrt{2}}{16}\right) \mathrm{a}=\frac{\pi}{4} ;$ Area of the circle $=\left(\frac{14-\sqrt{2}}{16}\right) \mathrm{a}^{2}$

$\mathrm{CB}=$ diameter $=\mathrm{a}$;

Draw a semicircle on $\mathrm{CB}$, with radius $\frac{\mathrm{a}}{2}$ and center $\mathrm{O}^{\prime} ; \quad \mathrm{CO}^{\prime}=\mathrm{O}^{\prime} \mathrm{B}=\frac{1}{2}$ where $\mathrm{a}=1$

Draw a perpendicular line on CB at I, which meets semicircle at Y. Apply altitude theorem to obtain IY length.

$$
\mathrm{IY}=\sqrt{\mathrm{CI} \times \mathrm{IB}}=\sqrt{\left(\frac{14-\sqrt{2}}{16}\right)\left(\frac{2+\sqrt{2}}{16}\right)}=\frac{\sqrt{26+12 \sqrt{2}}}{16}
$$

Connect YC which is the side of the square CYUT whose area is equal to that of the inscribed circle in the square ABCD.

Apply Pythagorean theorem to get CY from the triangle CIY

$$
\text { Side of the square } \mathrm{CY}=\sqrt{\mathrm{CI}^{2}+\mathrm{IY}^{2}}=\sqrt{\left(\frac{14-\sqrt{2}}{16}\right)^{2}+\left(\frac{\sqrt{26+12 \sqrt{2}}}{16}\right)^{2}}=\frac{\sqrt{14-\sqrt{2}}}{4}
$$

Area of the square CYUT $=\left(\frac{\sqrt{14-\sqrt{2}}}{4}\right)^{2}=\frac{14-\sqrt{2}}{16}=$ area of the inscribed circle in the square ABCD.

\section{Conclusion}

$\frac{14-\sqrt{2}}{4}$ is the exact $\pi$ value of circle. Hence, squaring of circle is done now. The misnomer "Circle squarer" will sink into oblivion. Hippocrates will now gets his deserving throne of greatness though delayed unfortunately for 2400 years. 